\title{
Syndrome differentiation of vitiligo and its munzich and mushil therapy based on traditional Uighur medicine theory
}

\begin{abstract}
Objective In this study, on 341 cases of vitiligo patients in line with the inclusion criteria were conducted syndrome differentiation typing analysis on admission and undergone Munzij and Mushil therapy to analyze the different syndrome differentiation types and the top ten symptoms that most intensively associate with them.

Methods On this basis, quantitative assessment were conducted on white spots and pigment regeneration area and the symptoms before and after the use of Munzij and Mushil. And with multivariate statistical analysis, analysis was conducted between correlation of Munzij and Mushil therapy to restore the vitiligo systemic pathological changes.

Results Compared with the time of admission, the white spots mean total area of patients has significantly narrowed $(\mathrm{P}<0.01)$ after the use Munzij and Mushil, leukoplakia district obvious pigment regeneration $(\mathrm{P}<0.01)$, symptoms improved significantly $(\mathrm{P}<0.01)$.

Conclusion Vitiligo is caused by strong concentrated phlegm, by which the transformation force and the exclusion force of the body weakened, so that the metabolic productions of the body cannot be excreted properly, and cause the vitiligo lesion to occur. Munzij and Mushil therapy is to correct abnormal temperament, to promote the generation of normal Hilits (body fluids) and restore the body's natural forces to control the proliferation of leukoplakia. The result of this research is consistent with the records. The results of this research proved points of ancient scholars from the point of view of modern medicine combined with Traditional Uighur Medicine theory.
\end{abstract}

Keywords: uighur medicine, vitiligo, syndrome differentiation, munzij and mushil therapy
Volume II Issue 4 - 2018

\author{
Silafu Aibai,' Tuerxun Wufuer, ${ }^{2}$ Abudujilili \\ Abuduaini ${ }^{1,3}$ \\ 'Institute of Xinjiang Traditional Uighur Medicine, China \\ 2Uighur Medicine Hospital of Xinjiang Uighur Autonomous \\ Region, China \\ ${ }^{3}$ University of Chinese Academy of Sciences, China
}

Correspondence: Silafu Aibai, Institute of Xinjiang Traditional Uighur Medicine, Urumqi 830049, China, Email abrallik68@sina.cn

Received: June 18, 2018| Published: July 12, 2018

\section{Introduction}

Vitiligo, named Baras in Uighur medicine, is a common disease with acquired depigmentation of skin and mucous membrane, manifested as localized or generalized depigmentation patches on skin and its incidence is rising..$^{1-8}$ According to the Guidelines for Diagnosis and Treatment of Vitiligo in Uighur Medicine, ${ }^{1-5}$ vitiligo is classified six types as Sweet Balgham Type vitiligo, Shor Balgham Type vitiligo, Kirtak Balgham Type vitiligo, Tamsiz Balgham Type vitiligo, Chuchumal Balgham Type vitiligo, Gajsiman Balgham Type vitiligo. In this research, based on the theory of Uighur Medicine, correlation analysis was undergone between vitiligo syndrome differentiation and Munzij and Mushil Therapy.,99

\section{Materials and methods}

\section{Patient recruitment and basic characteristics}

341 patients with vitiligo, aged 18-65years, who were attending the Xinjiang Uighur Medicine Hospital from October 2010 to June 2012, were recruited into the study. All were receiving treatment at the Xinjiang hospital for traditional Uighur Medicine in Urumqi, inpatients treated with Munzij and Mushil therapy greater than $(15+3)$ days, and all were in the active stages of vitiligo diagnosed according to the inclusion criteria described below.

\section{Inclusion and exclusion criteria ${ }^{3}$}

Inclusion criteria: Patients aged 18 to 65 years old who had been diagnosed with vitiligo in accordance with the standards set by the Guidelines for the Diagnosis and Treatment of Vitiligo in Uighur Medicine $^{11}$ and the Pigment Disease Study Group, Dermatology and Venereology Professional Committee, of the China Society of Integrated Traditional Chinese and Western Medicine, and who had given their informed consent.

Exclusion criteria: Patients aged below 18 or over 65years; women who were pregnant, lactating or menopausal; patients with other autoimmune, endocrine, psychiatric, liver, kidney, cardiovascular and allergic diseases; patients taking hormonal, oral contraceptive, or immunosuppressive agents; those who had been on corticosteroid or photochemical therapy in the last month; patients who were allergic to at least 2 kinds of food or drugs. ${ }^{4}$

\section{Treatment}

Patients were administered Munzij (abnormal balgham ripening agent) first, $3 / \mathrm{d}$, oral, continuously $12 \pm 3 \mathrm{~d}$, when the top ten syndrome symptoms mostly associated with the different dialectical types improved and the skin white spots began to itch, ceased expanding, even some parts started coloring, concentric narrowing, patients 
started using abnormal Balgham Mushil (abnormal balgham cleaning agent), oral, continuously $3 \mathrm{~d}$.

\section{Criterion for the curative effect}

Guidelines for the Diagnosis and Treatment of Vitiligo in Uighur Medicine. Journal of Medicine \& Pharmacy of Chinese Minorities, $2008 .^{3}$

\section{Statistics}

SPSS 18.0 statistical software was used to compare the data, using a non-parametric (Wilcoxon) test. Analysis of variance was carried out to explore any association between traditional Uighur medicine dialectical typing.

\section{Results}

The abnormal humor distribution (Table I)

Correlativity of different dialectical types and the top ten syndrome symptoms mostly associated with them (Tables 2-5)

Vitiligo symptom index changes at the different observation points during treatment of munzij and mussel (Table 6)

Effect of munzij and mushil therapy on the top ten symptoms of different types of vitiligo(Table 7)
Table I Analysis of the abnormal humor distribution

\begin{tabular}{lll}
\hline & Frequency & Percentage \\
\hline Sweet Balgham Type & 26 & 7.6 \\
Shor Balgham Type & 93 & 27.3 \\
Kirtak Balgham Type & 31 & 9.1 \\
Tamsiz Balgham Type & 118 & 34.6 \\
Chuchumal Balgham Type & 53 & 15.5 \\
Gajsiman Balgham Type & 20 & 5.9 \\
Total & 341 & 100 \\
\hline
\end{tabular}

Sweet balgham type vitiligo (Table 8)

Shor balgham type vitiligo (Table 9)

Chuchumal balgham type vitiligo (Table 10)

Kirtak balgham type vitiligo (Table II)

Tamsiz balgham type vitiligo

Gajsiman balgham type vitiligo

Table 2 six different dialectical types and the top ten syndrome symptoms mostly associated with them

\begin{tabular}{llll}
\hline Sweet balgham type & \multicolumn{2}{c}{ Shor balgham type } \\
\hline Symptoms & Relevance & Symptoms & Relevance \\
\hline Sweet-mouth feel sweet & $0.847^{* *}$ & Shor-tongue's red tend to yellow & $0.773^{* *}$ \\
Sweet- wide \& slow pulse & $0.713^{* *}$ & Shor-bitter taste dry tongue & $0.717^{* *}$ \\
Sweet- tired and sleepy & $0.404^{* *}$ & Shor-feel low heat & $0.683^{* *}$ \\
Sweet-thin grey coated tongue & $0.370^{* *}$ & Shor-dark red tongue & $0.680^{* *}$ \\
Sweet- tip of the tongue is red & $0.369^{* *}$ & Tamsiz- cold limbs and fear of cold & $-0.570^{* *}$ \\
Sweet-wide and thick tongue & $0.300^{* *}$ & Kirtak- hand foot chills & $-.0546^{* *}$ \\
Tamsiz- wide and thick tongue & $0.272^{* *}$ & Shor- thin, weak and uneven pulse & $0.542^{* *}$ \\
Tamsiz- cold limbs and fear of cold & $-0.254^{* *}$ & Kirtak- feel cold by oneself & $-0.436^{* *}$ \\
Kirtak-hand foot chills & $-0.249^{* *}$ & Shor- deep-colored urine & $0.423^{* *}$ \\
Sweet-feel heat by oneself & $0.249^{* *}$ & Sweet- feel heat by oneself & $0.384^{* *}$ \\
\hline
\end{tabular}

Table 3 six different dialectical types and the top ten syndrome symptoms mostly associated with them

\begin{tabular}{llll}
\hline Chuchumal balgham type & & Kirtak balgham type & Relevance \\
\hline Symptoms & Relevance & Symptoms & $0.663^{* *}$ \\
\hline Chuchumal-with usual skin allergy & $0.578^{* *}$ & Kirtak- hand foot chills & $0.635^{* *}$ \\
Chuchumal- thin and uneven pulse & $0.416^{* *}$ & Kirtak- feel low heat & $0.613^{* *}$ \\
Shor- thin and uneven pulse & $0.295^{* *}$ & Kirtak-thin and slow pulse & $0.466^{* *}$ \\
Tatlik-tip of tongue is red & $0.26 I^{* *}$ & Tamsiz- cold limbs and fear of cold & $-0.425^{* *}$ \\
Kirtak-feel chilly oneself & $-0.19 I^{* *}$ & Shor- tongue's red tend to yellow & $-0.424^{* *}$ \\
Gajsiman- uneven pulse & $0.183^{* *}$ & Shor- feel low heat & $0.384^{* *}$ \\
Kirtak- hand foot chills & $-0.180^{* *}$ & Kirtak- chloasma & $-0.382^{* *}$ \\
Tatlik- feel heat by oneself & $0.176^{* *}$ & Shor- thin, weak and uneven pulse & $0.37 I^{* *}$ \\
Tamsiz-thin white coated tongue & $-0.172^{* *}$ & Kirtak-tendency of pessimism & $-0.359^{* *}$ \\
Tamsiz- cold limbs and fear of cold & $-0.165^{* *}$ & Tatlik- feel heat by oneself & \\
\hline
\end{tabular}


Table 4 six different dialectical types and the top ten syndrome symptoms mostly associated with them (3)

\begin{tabular}{llll}
\hline Tamsiz balgham type & & Gajsiman kirtak balgham type & Relevance \\
\hline Symptoms & Relevance & Symptoms & $0.440^{* *}$ \\
\hline Tamsiz-thick but weak pulse & $0.797^{* *}$ & Gajsiman-thin, slow, weak pulse & $0.419^{* *}$ \\
Tamsiz-increased saliva & $0.749^{* *}$ & Gajsiman-upset and impatient & $0.352^{* *}$ \\
Tamsiz-more urine light color & $0.697^{* *}$ & Gajsiman-uneven pulse & $-0.208^{* *}$ \\
Tamsiz- moist skin & $0.567^{* *}$ & Shor-dark red tongue & $-0.159^{* *}$ \\
Tamsiz- thin white coated tongue & $0.493^{* *}$ & Tamsiz- wide and thick tongue & $-0.137^{*}$ \\
Tamsiz- wide and thick tongue & $0.477^{* *}$ & Shor- tongue's red tend to yellow & $-0.133^{*}$ \\
Tatlik - wide and thick tongue & $0.399^{* *}$ & Tamsiz- increased saliva & $-0.130^{*}$ \\
Tamsiz- cold limbs and fear of cold & $0.397^{* *}$ & Tatlik- tip of tongue is red & $-0.125^{*}$ \\
Tatlik-more urine & $0.34 I^{* *}$ & Shor- deep-coloured urine & 0.050 \\
Shor - bitter taste dry tongue & $-0.30 I^{* *}$ & Kirtak-white hair on white spot & \\
\hline
\end{tabular}

Table 5 Percentage of vitiligo symptom index changes at the different observation points during treatment of Munzij and Mussil

\begin{tabular}{|c|c|c|c|c|}
\hline \multirow{2}{*}{$\begin{array}{l}\text { Abnormal humor } \\
\text { types }\end{array}$} & \multicolumn{3}{|c|}{ Percentage of Symptoms (changes at different observation points) } & \multirow{2}{*}{ Statistics } \\
\hline & Before treatment & After treated with Munzij & $\begin{array}{l}\text { After treated } \\
\text { with Munzij and Mussil }\end{array}$ & \\
\hline Sweet balgham type & $21.30 \pm 22.13$ & $9.09 \pm 12.21$ & $5.72 \pm 9.92$ & $P<0.05$ \\
\hline Shor balgham type & $31.09 \pm 34.89$ & $8.87 \pm 13.77$ & $4.93 \pm 8.63$ & $P<0.05$ \\
\hline Chuchumal balgham type & $|4.6| \pm 23.09$ & $2.24 \pm 8.33$ & $0.68 \pm 4.72$ & $P<0.05$ \\
\hline Kirtak balgham type & $39.4 I \pm 24.68$ & $12.61 \pm \mid 4.1$ & $8.87 \pm 11.19$ & $P<0.05$ \\
\hline Tamsiz balgham type & $25.04 \pm 27.90$ & $8.34 \pm 11.54$ & $4.67 \pm 8.94$ & $P<0.05$ \\
\hline Gajsiman balgham type & $17.50 \pm 24.19$ & $3.4 I \pm 10.74$ & $1.27 \pm 6.36$ & $P<0.05$ \\
\hline
\end{tabular}

Table 6 Top ten symptoms of 26 cases of Sweet Balgham type vitiligo and symptom changes after treated with Munzij and Mushil

\begin{tabular}{|c|c|c|c|c|c|c|c|}
\hline \multirow[b]{2}{*}{ Order } & \multirow[b]{2}{*}{ Symptoms } & \multicolumn{6}{|c|}{ Different observation points } \\
\hline & & \multicolumn{2}{|c|}{ Before treatment } & \multicolumn{2}{|c|}{$\begin{array}{l}\text { After treated with } \\
\text { munzij }\end{array}$} & \multicolumn{2}{|c|}{$\begin{array}{l}\text { After treated with both } \\
\text { munzij and mushil }\end{array}$} \\
\hline I & Wide \& slow pulse & 25 & 0.96 & 8 & 0.31 & 0 & 0.00 \\
\hline 3 & Sweet taste mouth & 24 & 0.92 & 7 & 0.27 & 2 & 0.08 \\
\hline 4 & White and shiny leukoplakia & 24 & 0.92 & 7 & 0.27 & $\mathrm{I}$ & 0.04 \\
\hline 5 & Wide and thick tongue & 22 & 0.85 & 15 & 0.58 & 3 & 0.12 \\
\hline 8 & Tired and sleepy & 18 & 0.69 & 0 & 0.00 & 0 & 0.00 \\
\hline 9 & Feel heat by oneself & 17 & 0.65 & 4 & 0.15 & I & 0.04 \\
\hline 10 & More urine & 17 & 0.65 & 7 & 0.27 & 0 & 0.00 \\
\hline
\end{tabular}


Table 7 Top ten symptoms of 93 cases of Shor Balgham type vitiligo and symptom changes after treated with Munzij and Mushil

\begin{tabular}{|c|c|c|c|c|c|c|c|}
\hline \multirow{2}{*}{ Order } & \multirow{2}{*}{ Symptoms } & \multicolumn{6}{|c|}{ Different observation points } \\
\hline & & $\begin{array}{l}\text { Number } \\
\text { of cases }\end{array}$ & $\begin{array}{l}\text { Positive } \\
\text { rate }\end{array}$ & $\begin{array}{l}\text { Number } \\
\text { of cases }\end{array}$ & $\begin{array}{l}\text { Positive } \\
\text { rate }\end{array}$ & $\begin{array}{l}\text { Number of } \\
\text { cases }\end{array}$ & $\begin{array}{l}\text { Positive } \\
\text { rate }\end{array}$ \\
\hline I & Dark red tongue & 89 & 0.96 & 65 & 0.70 & 30 & 0.32 \\
\hline 3 & Tongue's red tend to yellow & 82 & 0.88 & II & 0.12 & 3 & 0.03 \\
\hline 4 & White and shiny leukoplakia & 82 & 0.88 & 17 & 0.18 & 6 & 0.06 \\
\hline 5 & Feel low heat & 80 & 0.86 & 16 & 0.17 & 4 & 0.04 \\
\hline 6 & Thin, weak and uneven pulse & 67 & 0.72 & 10 & 0.11 & 2 & 0.02 \\
\hline 9 & Tip of tongue is red & 41 & 0.44 & 18 & 0.19 & 9 & 0.10 \\
\hline 10 & Thin, weak and uneven pulse & 36 & 0.39 & 6 & 0.06 & 1 & 0.01 \\
\hline
\end{tabular}

Table 8 Top ten symptoms of 3 I cases of Chuchumal Balgham type vitiligo and symptom changes after treated with Munzij and Mushil

\begin{tabular}{|c|c|c|c|c|c|c|c|}
\hline \multirow{3}{*}{ Order } & \multirow{3}{*}{ Symptoms } & \multicolumn{6}{|c|}{ Different observation points } \\
\hline & & \multicolumn{2}{|c|}{ Before treatment } & \multicolumn{2}{|c|}{$\begin{array}{l}\text { After treated with } \\
\text { munzj }\end{array}$} & \multicolumn{2}{|c|}{$\begin{array}{l}\text { After treated with both } \\
\text { munzij and mushil }\end{array}$} \\
\hline & & $\begin{array}{l}\text { Number } \\
\text { of cases }\end{array}$ & $\begin{array}{l}\text { Positive } \\
\text { rate }\end{array}$ & $\begin{array}{l}\text { Number } \\
\text { of cases }\end{array}$ & $\begin{array}{l}\text { Positive } \\
\text { rate }\end{array}$ & $\begin{array}{l}\text { Number of } \\
\text { cases }\end{array}$ & $\begin{array}{l}\text { Positive } \\
\text { rate }\end{array}$ \\
\hline I & White and shiny leukoplakia & 29 & 0.94 & 6 & 0.19 & 5 & 0.16 \\
\hline 2 & Tip of tongue is red & 23 & 0.74 & 8 & 0.26 & 5 & 0.16 \\
\hline 3 & Thin, weak and uneven pulse & 23 & 0.74 & I & 0.03 & 0 & 0.00 \\
\hline 4 & With usual skin allergy & 23 & 0.74 & 12 & 0.39 & 2 & 0.06 \\
\hline 5 & Feel heat by oneself & 16 & 0.52 & 0 & 0.00 & 0 & 0.00 \\
\hline 6 & Feel low heat & 16 & 0.52 & 1 & 0.03 & 0 & 0.00 \\
\hline 7 & Tongue's red tend to yellow & 14 & 0.45 & I & 0.03 & 0 & 0.00 \\
\hline 8 & Bitter taste dry tongue & 12 & 0.39 & 0 & 0.00 & 0 & 0.00 \\
\hline 9 & Sometimes uneven & 12 & 0.39 & 2 & 0.06 & 0 & 0.00 \\
\hline 10 & Thin grey coated tongue & 11 & 0.36 & 3 & 0.09 & I & 0.03 \\
\hline
\end{tabular}

Table 9 Top ten symptoms of II 8 cases of Kirtak Balgham type vitiligo and symptom changes after treated with Munzij and Mushil

\begin{tabular}{|c|c|c|c|c|c|c|c|}
\hline \multirow{3}{*}{ Order } & \multirow{3}{*}{ Symptoms } & \multicolumn{6}{|c|}{ Different observation points } \\
\hline & & \multicolumn{2}{|c|}{ Before treatment } & \multicolumn{2}{|c|}{$\begin{array}{l}\text { After treated with } \\
\text { munzj }\end{array}$} & \multicolumn{2}{|c|}{$\begin{array}{l}\text { After treated with both } \\
\text { munzij and mushil }\end{array}$} \\
\hline & & $\begin{array}{l}\text { Number } \\
\text { of cases }\end{array}$ & $\begin{array}{l}\text { Positive } \\
\text { rate }\end{array}$ & $\begin{array}{l}\text { Number } \\
\text { of cases }\end{array}$ & $\begin{array}{l}\text { Positive } \\
\text { rate }\end{array}$ & $\begin{array}{l}\text { Number of } \\
\text { cases }\end{array}$ & $\begin{array}{l}\text { Positive } \\
\text { rate }\end{array}$ \\
\hline I & Hand foot chills & 114 & 0.97 & 40 & 0.34 & 21 & 0.18 \\
\hline 2 & White and shiny leukoplakia & 111 & 0.94 & 53 & 0.45 & 42 & 0.36 \\
\hline 3 & Feel cold by oneself & 110 & 0.93 & 18 & 0.15 & 8 & 0.07 \\
\hline 4 & Cold limbs and fear of cold & 99 & 0.84 & 29 & 0.25 & $\mathrm{II}$ & 0.09 \\
\hline 5 & Tendency of pessimism & 93 & 0.79 & 27 & 0.23 & 12 & 0.10 \\
\hline 6 & Thin and slow pulse & 85 & 0.72 & 20 & 0.17 & 14 & 0.12 \\
\hline 7 & White coated tongue & 55 & 0.47 & 17 & 0.14 & 4 & 0.03 \\
\hline 8 & White hair on white spot & 48 & 0.41 & 36 & 0.31 & 36 & 0.31 \\
\hline 9 & Chloasma & 45 & 0.38 & 35 & 0.30 & 30 & 0.25 \\
\hline 10 & Grey coated tongue & 43 & 0.36 & II & 0.09 & 6 & 0.05 \\
\hline
\end{tabular}


Table 10 Top ten symptoms of 53 cases of Tamsiz Balgham type vitiligo and symptom changes after treated with Munzij and Mushil

\begin{tabular}{|c|c|c|c|c|c|c|c|}
\hline \multirow{3}{*}{ Order } & \multirow{3}{*}{ Symptoms } & \multicolumn{6}{|c|}{ Different observation points } \\
\hline & & \multicolumn{2}{|c|}{ Before treatment } & \multicolumn{2}{|c|}{$\begin{array}{l}\text { After treated with } \\
\text { munzij }\end{array}$} & \multicolumn{2}{|c|}{$\begin{array}{l}\text { After treated with both } \\
\text { munzij and mushil }\end{array}$} \\
\hline & & $\begin{array}{l}\text { Number } \\
\text { of cases }\end{array}$ & $\begin{array}{l}\text { Positive } \\
\text { rate }\end{array}$ & $\begin{array}{l}\text { Number } \\
\text { of cases }\end{array}$ & $\begin{array}{l}\text { Positive } \\
\text { rate }\end{array}$ & $\begin{array}{l}\text { Number of } \\
\text { cases }\end{array}$ & $\begin{array}{l}\text { Positive } \\
\text { rate }\end{array}$ \\
\hline I & White coated tongue & 53 & 1.00 & 5 & 0.09 & 1 & 0.02 \\
\hline 2 & Cold limbs and fear of cold & 52 & 0.98 & 3 & 0.06 & 2 & 0.04 \\
\hline 3 & Moist skin & 51 & 0.96 & 3 & 0.06 & 0 & 0.00 \\
\hline 4 & Increased saliva & 50 & 0.94 & 2 & 0.04 & 2 & 0.04 \\
\hline 5 & Thick but weak pulse & 48 & 0.91 & 5 & 0.09 & 2 & 0.04 \\
\hline 6 & Wide and thick tongue & 47 & 0.89 & 31 & 0.58 & 13 & 0.25 \\
\hline 7 & More urine light color & 47 & 0.89 & 4 & 0.08 & 3 & 0.06 \\
\hline 8 & White and shiny leukoplakia & 44 & 0.83 & 5 & 0.09 & 4 & 0.08 \\
\hline 9 & Wide and thick tongue & 42 & 0.79 & 29 & 0.55 & 12 & 0.23 \\
\hline 10 & Hand foot chills & 37 & 0.70 & 2 & 0.04 & 2 & 0.04 \\
\hline
\end{tabular}

Table I I Top ten symptoms of 20 cases of Gajsiman Balgham type vitiligo and symptom changes after treated with Munzij and Mushil

\begin{tabular}{|c|c|c|c|c|c|c|c|}
\hline \multirow{3}{*}{ Order } & \multirow{3}{*}{ Symptoms } & \multicolumn{6}{|c|}{ Different observation points } \\
\hline & & \multicolumn{2}{|c|}{ Before treatment } & \multicolumn{2}{|c|}{$\begin{array}{l}\text { After treated with } \\
\text { munzij }\end{array}$} & \multicolumn{2}{|c|}{$\begin{array}{l}\text { After treated with both } \\
\text { munzij and mushil }\end{array}$} \\
\hline & & $\begin{array}{l}\text { Number } \\
\text { of cases }\end{array}$ & $\begin{array}{l}\text { Positive } \\
\text { rate }\end{array}$ & $\begin{array}{l}\text { Number } \\
\text { of cases }\end{array}$ & $\begin{array}{l}\text { Positive } \\
\text { rate }\end{array}$ & $\begin{array}{l}\text { Number of } \\
\text { cases }\end{array}$ & Positive rate \\
\hline I & Thin, slow, weak pulse & 20 & I & 4 & 0.2 & 4 & 0.2 \\
\hline 2 & Upset and impatient & 17 & 0.85 & 4 & 0.2 & 2 & 0.1 \\
\hline 3 & White and shiny leukoplakia & 17 & 0.85 & 4 & 0.2 & 3 & 0.15 \\
\hline 4 & Uneven pulse & 14 & 0.7 & 8 & 0.4 & 3 & 0.15 \\
\hline 5 & Cold limbs and fear of cold & II & 0.55 & 3 & 0.15 & 1 & 0.05 \\
\hline 6 & Tendency of pessimism & 9 & 0.45 & 1 & 0.05 & 0 & 0 \\
\hline 7 & Thin and slow pulse & 8 & 0.4 & 4 & 0.2 & 2 & 0.1 \\
\hline 8 & Hand foot chills & 8 & 0.4 & 4 & 0.2 & 2 & 0.1 \\
\hline 9 & White and shiny leukoplakia & 8 & 0.4 & 8 & 0.4 & 7 & 0.35 \\
\hline 10 & Thin, weak and uneven pulse & 7 & 0.35 & 0 & 0 & 0 & 0 \\
\hline
\end{tabular}

\section{Discussion}

In this study, vitiligo patients meeting the inclusion criteria were classified according to Uighur medical syndrome types and their risk factors, the original temperament and abnormal distribution of body fluid, the influence factors and the top ten syndrome symptoms mostly associated with different dialectical types were analyzed. Then leukoplakia and pigment regeneration area and symptoms were evaluated quantitatively after treated with Munzij and Mushil, using the method of multivariate statistical analysis, the incidence, inducement and effect factors of vitiligo and the correlation of Munzij and Mushil to the recovery of the internal environment changes of patients with vitiligo were analyzed as well. As the result, kirtak balgham type accounted for $34.6 \%$ of all types in this project, because vitiligo patients' dry cold or wet cold temperament surplus others, moreover eating habits and mental factors are important inducement.
These results conform to the record "Kirtak Balgham has both excessive moisture and excessive cold characteristics and one of the typical types of abnormal balgham hilit, therefore Kirtak Balgham type vitiligo is the most common one" ${ }^{5,10,11}$ in Uighur medical classic Medicinal Database.

Treatment of vitiligo with Uighur Medicine has unique and significant effect with food taboos, the use of comprehensive treatment of Munzij, Mussil, other drugs and non-drug methods. Being on diet is to prevent further imbalance of body temperament, to let the patient eat hot food to increase the heat of liver for nutrition supplement and to promote the abnormal humor mature and regulate the abnormal temperament to create healthy internal environment, so as to help drugs have full effect. At first Munzij and Mussil is applied for treatment to mature and eliminate the abnormal humor, correcting the abnormal temperament then to promote the formation of normal 
Hilit (body fluid), restoring the functions of all organs and the body natural force then is applied comprehensive therapy. The results of this study show that, compared with the results of admission, after treated with Munzij and Mussil (maturing and eliminating abnormal Hilit) vitiligo symptoms percentage at different observation points proved vitiligo symptoms improved significantly $(\mathrm{P}<0.01)$, the average total white area was significantly reduced $(\mathrm{P}<0.01)$, leukoplakia region obviously pigment regeneration $(\mathrm{P}<0.01)$. Munzij and Mussil therapy by maturing and eliminating the abnormal Balgham Hilit, regulating the internal environment, improving the natural force can improve internal environment and control the development of the disease. ${ }^{12}$

The results proved that the famous sayings in ancient medical books "Canon of Medicine" by Avi Sena in Eleventh Century and "Tippy Akbar" by Mohammed Akbar Ali in the 1750 A.D. : "Vitiligo is caused by abnormal accumulation of Balgham Hilit in body causing the body unable to eliminate the produced abnormal body fluids out of body. Maturing and removing abnormal body fluids can correct the abnormal temperament, promote the formation of normal body fluid, restoring the body force of nature, so as to control the white spot diffusion ". These results provided a basis for healing and shortening the course of treatment for vitiligo with Uighur medicine intervention treatment, at the same from the angle of modern medicine, with Uighur medical Disease and Syndrome Theory, we also analyzed vitiligo Uighur medicine dialectical typing standard, correlation of Munzij and Mushil therapy to restoring systemic pathological changes of vitiligo. Foundation was laid for the standardization of diagnosis and the treatment of abnormal humor symptoms.

\section{Competing interests}

The author(s) declared no potential conflicts of interest with respect to the research authorship and/or publication of this article.

\section{Ethics approval}

Thestudy was approved by theXinjiang Traditional UighurMedicine Hospital Ethics Committee (Project no. XJTUMHE20100611L).

\section{Author's contributions}

Silafu Aibai conceived of the study, and participated in its design and coordination and performed general analysis. Tuerxun Wufuer participated in the design of the study and performed parts of the statistical analysis and carried out the diagnosis and symptom assessment. Abudujilili Abuduaini wrote the manuscript, and performed the acquisition of data and the statistical analysis and carried out acquisition of data and some statistical analysis.

\section{Acknowledgements}

This research was supported by the Science and Technology Personnel Training Project of Administration Bureau of Traditional Chinese Medicine and Ethnic Group Medicine of Xinjiang Uyghur Autonomous Region (Grant no. 2016-03-04).

\section{Conflict of interest}

The author declares no conflict of interest.

\section{References}

1. Tuerxun W, Silafu A, Ysufu M. Guidelines for the Diagnosis and Treatment of Vitiligo in Uighur Medicine. Journal of Medicine \& Pharmacy of Chinese Minorities. 2008;8:61-63.

2. Tuerxun Wufuer, Silafu Aibai, Refuhati Saimaiti. Uighur Medicine Syndrome Differentiation Analysis of 1051 cases of vitiligo. Journal of Chinese Dermatovenerology.2006;11(24):1056-1057.

3. Tursun G, Yusup M, Repkat S, et al. Observation of the Role of Munziq and Mus'hil Therapy in Vitiligo. Chin J Derm Venereol. 2012;26:80-82.

4. Jurat Tohti, Turgun Amar, Sirap Abai. Retrospective Survey and Analysis on Vitiligo Treatment by Uighur Medicine. Chinese Journal of Information on TCM. 2011;18:24-26.

5. Muhammad Yusuf. Ahsaray Adwiya. (M) (In Persian, AD 1763):233-234.

6. Mattoo SK, Handa S, Kaur I, et al. Psychiatric morbidity in vitiligo and psoriasis: acomparative study from India. J Dermatol. 2001;28(8):424 432 .

7. Sharma N, Koranne RV, Singh RK. Psychiatric morbidity in psoriasis and vitiligo: a comparative study. J Dormatol. 2001;28(8):419- 423.

8. Mattoo SK, Handa S, Kaur I, et al. Psychiatric morbidity in vitiligo: prevalence and correlates in India. J Eur Acad Dermatol Venereo. 2002;16(6):573- 578 .

9. Silafu Aibai, Tuerxun Wufuer, Aizezi Yasen. Study on the correlation of Uighur medical treatment and neuroendocrine immune function of vitilig. Pharmacology and Clinics of Chinese Materia Medica. 2012;28(3):156161.

10. Silafu Aibai, Mainisha Maimaiti, Tuerxun Wufuer, et al. Clinical Research Guidelines for the Treatment of Vitiligo with new Uighur Medicine. Chinese Journal of Information on TCM. 2015;22(5):115-118.

11. Hakim Ali Sultan. Dasturul Ilaj (M). Urumqi: Xinjiang Health Publishing House; 1998. p. 821-823. 